\title{
Book Review: disruptive classroom technologies: a framework for innovation in education (Magana, S., 2017)
}

\author{
Nadine Jaafarawi \\ Afshan Parkar
}

Zayed University, UAE

In his book, Disruptive classroom technologies (Corwin/Sage Publications), Magana stresses the notion that since globalization is increasing along with the application of information and communication technologies, the recent modern and learning environments should also reflect those changes. However, there is no noticeable impact of educational technology tools on student achievement. From this point Magana suggests, in his book, an actionable framework for educational technology use that relies on emphasizing pedagogical principles and strategies and the ways teachers can enhance these principles and practices with their available classroom technologies. It is also important to track the impact of this implementation on student social and academic success. Consequently, this will not only improve student learning outcomes but also prepare students for social and professional success in this digital age. Later on, he examines two existing frameworks: Technological Pedagogical Content Knowledge (TPACK) and Substitution-Augmentation-Modification-Redefinition (SAMR), and comments that neither sufficiently helps in attaining the technological knowledge needed to implement the use of technology in the classroom. To avoid any misinterpretation or misapplication of those models, Magana introduces the T3 framework as a new way to frame how we think about innovative technology used in education: translational technology use, transformational technology use, and transcendent technology use. Early phases of innovation, which Magana describes as "automation" and "consumption", represent translational uses of educational technology. However, applying those two stages and expecting transformational results is, as he describes, insane. Yet that is what seems to be happening in educational systems the world over: teachers and students engage in fundamentally translational technology uses but expect transformational outcomes. To avoid such misapplication of these concepts, there should be a realization of high value uses of technology in teaching and learning.

In his T3 framework, Magana stresses the importance of the transformational stage, and describes it as a necessary second step towards realizing the much higher value added by the use of technology in the service of contributive teaching and learning. By placing students firmly at the center of classroom experiences and raising their mindset to a new and superior state than that which existed prior to the learning experience we are unleashing students limitless learning potentials and reaching notable goals of education. This takes us to the third stage which is the transcendent use of educational technology which places controversial problems that matter to students at the center of their learning experience. This stage helps students to go beyond the expected learning experience and motivate them to pose powerful open-minded questions: "What if...?" Consequently, the experiences gained go far above and beyond known ranges of expectations and there will be no limits regarding what students will discover when solving problems about which they are passionate. The core objective of Magana, in this book, is to make the T3 framework actionable. This model provides a clear, more precise framework to guide teachers and leaders in self-assessing current uses of the technology. In the last section, Magana provides a guide for leaders to collaborate with the teachers on monitoring and tracking progress towards their professional growth goals. 
In the Gulf Region, the students are used to traditional lecturing by their instructors, who use power points, whiteboards and smartboards for teaching. On the other hand, those students are very techsavvy as they use a lot of electronics on a day to day basis, such as phones, laptops, iPad etc. That is why we should not deny the fact that instructors are not introduced to incorporating Technology in the classroom with their teaching content and their pedagogy. This book will aid instructors to incorporate technology with their teaching content and pedagogy to maximize the student learning and engagement with the course.

This book is significant as it sheds the light on our need to build collaborative communities of students solving problems, explaining to others (regardless of ability) and using the social media aspects of technology to change classroom conversations from monologue to dialogue. All instructors in Gulf institutions should read this book to get insight about how to incorporate the use of technology with their course content and pedagogy to foster students' learning and engagement in the course. They can read the book for professional development as it will help them keep updated with the latest technological tools that they can use in their classrooms. However, if the instructor does not have a certain familiarity with the use of technological tools in his/her classroom then this book would be of less help to him, as it mainly focuses on how to collaborate in the use of various new innovative technological techniques in a disruptive classroom environment.

Overall, this book is recommended to any teacher who has a firm grip on teaching with technology but looking to get even stronger.

Our recent technological interventions do not necessarily change the "tell and practice" teaching model. Magana's T3 framework can help instructors to move beyond the translation and transforming current practices to transcendent uses of technology. We need to build collaborative communities of students solving problems, explaining to others and using recent online technologies to foster their learning. Also, by using the above-mentioned practices, the students will get the chance to follow the "learning by doing" technique. This will give them hands-on practice with the course and get them encountered with real-life situations.

The book bridges the gap between the learning institution and real life, integrating digital and cloudbased production technologies. The three stages in the T3 framework help educators reflect on the status quo of their technology. Such reflection helps in promoting self-assessment not only on the teachers' and learners' part, but also on the part of education administration.

The T3 Framework also helps teachers and students get emancipated from the myriad digital tools. Instead, they will focus on carving out a practical plan in specific teaching context and find proper solution with the technological tools that serve the learning process. By doing so technologies are more likely to bring out "disruptive" rather than "distractive" outcomes.

As a final note, the book does have certain limitations:

- The instructor needs to be aware of the use of technology and the skills required to learn the technology.

- Preparing lessons using a new technological tool could be time consuming.

- The students' knowledge regarding the new tool used can be limited and would need training in order to go ahead with the course- which would be again be time consuming.

- Certain technological tools are not free and, as an instructor, it is not feasible to use these tools with the limited options available.

- There could be technological mishaps in the classroom pertaining to the website or the use of tools in class if the instructor is not very experienced with the technological tool. 
- The author was negative in regard to automation and did not focus on the value of motivation with technology in low-level skills in form of addressing different learning styles or even how it helps in English language learners. His main focus was on users of technological tools that are just replacing print while he should have expanded more into pedagogically teaching students with low-level technological skills.

\section{References}

Ambrose, S. (2018, January 16). Review of the book Disruptive Classroom Technologies. [Book Review]. Retrieved from http://www.edcircuit.com/main-home/about-edcircuit/

Hattie, J. (2008). Visible learning: A synthesis of over 800 meta-analyses relating to achievement. London: Routledge.

Hilton, J. T. (2016). A case study of the application of SAMR and TPACK for reflection on technology integration into two social studies classrooms. The Social Studies, 107(2), 68-73.

Magana, S. (2017). Disruptive classroom technologies: A framework for innovation in education. Thousand Oaks, CA: Corwin.

Middleton, B. (2018, February 26). Reading Rumpus Book Reviews. [Review of the book Disruptive Classroom Technologies, by S. Magana]. Retrieved from http://barb-

middleton.blogspot.com/2018/02/disruptive-classroom-technologies.html 